\title{
STUDI KUALITATIF NILAI-NILAI EKOFEMINIS PADA KOMUNITAS KERAJINAN TENUN DI DESA SUKARARA KECAMATAN JONGGAT, LOMBOK TENGAH
}

\author{
Nur Choerun Nisa ${ }^{1}$ Nadiroh $^{1}$ \\ Universitas Negeri Jakarta \\ Email: nurchoerunnisa18@gmail.com
}

\begin{abstract}
Indonesia as an archipelago country, has a diversity of ethnic groups each with local knowledge. That is one of the creative culture of the Sasak tribe of Lombok. This craft is one of the results of human creativity to meet the needs of clothing. Sasak tribe who inhabit the island of Lombok, until now still preserving the weaving craft. One of the supporters of weaving sustainability is the availability of natural dyes derived from plants. In this study, data collection was conducted in Sukarara Village, Jonggat Subdistrict, Central Lombok District, West Nusa Tenggara Province which is one of the weaving centers in Lombok. The research method is direct observation in field and interview. The results of the research inform the role of women already considered in decision making concerning natural resources.
\end{abstract}

Keywords: women, weaving, coloring, Sasak tribe, natural resources 


\section{PENDAHULUAN}

Sebagian besar bentuk ekofeminisme bergantung pada analisis historis tentang ideologi. Menurut analisis ini, penindasan alam dan perempuan muncul dengan ideologi Barat yang disebut patriarki yang muncul sekitar 5.000 tahun yang lalu. Pemikiran patriarki Barat didasarkan pada 'dualisme', pandangan dunia yang memerintahkan dunia dengan membaginya menjadi pasangan konsep yang berlawanan: Pikiran terbelah dari tubuh, semangat dari materi, pria dari perempuan, budaya dari alam. Satu konsep di masingmasing pasangan dianggap lebih unggul dari yang lain. 'Yang lain' ini kadang-kadang dibuat jahat dan selalu didiskriminasikan. Konsep di kedua belah pihak terikat pada hubungan kompleks yang menjadi saling menguatkan. Kelompok yang tertindas di masyarakat kita sering dikaitkan dengan tubuh dan bukan dari pikiran. Perempuan diperlakukan lebih rendah daripada laki-laki, dan manusia dipahami terpisah darilingkungan alam (thegreenfuse.org).
Dalam artikel ini menawarkan pengenalan literatur dan nilai ekofeminisme yang ada dalam suatu komunitas desa. Kemudian mengidentifikasi koneksi yang disebut "hubungan perempuan-sifatalam" yang oleh para ekofeminis mengklaim bahwa mereka adalah dominasi perempuan dan alam (Warren, J Karen 1993)

Industri tekstil baik dalam skala besar maupun kecil tidak bisa dipisahkan dari penggunaan bahan pewarna. Dalam makalah ulasannya, Indrianingsih dan Darsih (2013) mengemukakan bahwa penggunaan bahan pewarna sintetis telah menyebabkan pencemaran lingkungan di pusat-pusat industri tekstil. Terlebih lagi, jenis-jenis pewarna sintetis sering mengandung logam berat yang tidak baik bagi kesehatan manusia yang dapat menimbulkan kanker, menyerang saraf otak, dan merusak lingkungan. Logam berat ini sangat berbahaya meskipun kadarnya relatif kecil,sangat mudah diserap, dan terakumulasi secara biologis oleh biota dalam perairan. Logam timbal 
apabila terserap dan terakumulasi pada tubuh manusia dapat mengganggu kesehatan (Pranoto et al. 2002).Beberapa dampak negatif akibat penggunaan bahan pewarna sintetis menyebabkan perlunya upaya untuk mengganti bahan-bahan tersebut dengan bahan-bahan alami yang lebih ramah lingkungan (Baliarsingh 2012). Mengingat pemakaian pewarna sintetis sangat berbahaya bagi kesehatan dan lingkungan, serta dengan semakin berkembangnya kesadaran 'kembali ke alam', penggunaan pewarna alami adalah alternatif pilihannya (Indrianingsih dan Darsih 2013). Perempuan memiliki hubungan yang erat dengan alam (Morgan, 1992, p. 4). Seiring adanya krisis lingkungan, perempuan memiliki kontrol yang sama kuatnya dengan laki-laki untuk membangun kesadaran dalam melestarikan bumi (King, 1990). Kerajinan menenun di Desa Sukarara Kecamatan Jonggat, Lombok Tengah dilakukan oleh sebagian besar perempuan. Perempuan yang memiliki peran dalam menjaga warisan budaya lokal dengan menggunakan bahan yang ramah lingkungan (CNN, Indonesia).

Perempuan desa yang bergantung hidupnya pada sumber daya alam kebanyakan menjadi korban dampak negatif pembangunan. Pada banyak komunitas pedesaan perempuan lah yang melakukan sebagian besar kegiatan pertanian. Akan tetapi, ketika tanah berada dibawah tekanan negara atau eksploitasi perusahaan, seringkali perempuan memiliki kontrol yang lebih rendah dibandingkan dengan laki-laki dalam pengambilan keputusan yang mempengaruhi tanah dan sumber daya alam mereka. (downtoearthindonesia).

\section{METODOLOGI}

Penelitian ini dilaksanakan di Desa Sukarara, Kecamatan Jonggat, Kabupaten Lombok Tengah, Provinsi Nusa Tenggara Barat. Letak Desa Sukarara sekitar $25 \mathrm{~km}$ dari Kota Mataram. Desa ini merupakan salah satu pusat kerajinan tenun di Lombok yang didiami oleh suku Sasak. Penelitian dilakukan pada bulan April 2017. 


$\begin{array}{llrlr}\text { Penelitian } & \text { tentang } & \text { nilai-nilai } & \text { maksimum". } & \text { Deskriptif } \\ \text { ekofeminis } & \text { ini } & \text { menggunakan } & \text { fenomenologi merangsang persepsi } \\ \text { penelitian } & \text { kualitatif } & \text { dengan } & \text { kita tentang pengalaman hidup dan } \\ \text { menggunakan } & & \text { pendekatan } & \text { menekankan pada kekayaan, } \\ \text { fenomenologi. Denzin dan Lincoln } & \text { keluasan, dan } & \text { kedalaman }\end{array}$

(1987) dan Moleong (2010)

menegaskan bahwa penelitian

kualitatif menggunakan latar ilmiah

yang bertujuan untuk menafsirkan

fenomena yang terjadi dan dilakukan

dengan menggunakan berbagai

macam metode seperti wawancara, pengamatan, dan pemanfaatan

dokumen.

Pengambilan

informasidilalukan pada responden kunci dan para perempuan pengrajin tenun. Data dan informasi yang dikumpulkan dalam penelitian ini meliputi deskripsi tentang tentang Nilai-Nilai Ekofeminis pada Komunitas Kerajinan Tenun Di Desa Sukarara Kecamatan Jonggat, Lombok Tengah dalam Rangka Memastikan Kelestarian Lingkungan Hidup.

Fenomenologi deskriptif melibatkan eksplorasi langsung, analisa, dan deskripsi fenomena tertentu, sebebas mungkin dari pengandaian teruji, dengan tujuan presentasi intuitif pengalaman-pengalaman.

Spiegelberg (1975) mengidentifikasi 3 langkah untuk proses fenomenologi deskriptif: Intuisi, Menganalisis, Menjelaskan.

Dalam penelitian kualitatif dengan pendekatan fenomenologi penentuan jumlah partisipan dapat ditentukan berdasarkan pendapat dari Creswell (1998), dimana ukuran sampel yang digunakan adalah 5-25 orang. Beberapa peneliti menyarankan untuk mementingkan tercapainya titik jenuh (Poerwandari, 2009). Pada penelitian ini menggunakan partisipan sebanyak 5 orang. Jumlah partisipan ditentukan karena data yang peneliti dapatkan telah mencapai saturasi pada partisipan ke5.

Teknik pengumpulan data dilakukan dengan melakukan kegiatan wawancara yang mendalam untuk menggali pengalaman perempuan 
suku Sasak dalam hubungannya dengan alam. Proses wawancara dilakukan secara informal. Bentuk pertanyaan yang digunakan adalah jenis pertanyaan terbuka agar para perempuan dapat menceritakan secara leluasa peran mereka dalam menciptakan keserasian dengan alam.

\section{HASIL DAN PEMBAHASAN}

Partisipan dalam penelitian ini adalah perempuan yang bekerja sebagai pembuat kerajian tenun yang terdiri dari 5 orang partisipan.

\begin{tabular}{|c|c|c|}
\hline Partisipan & $\begin{array}{c}\text { Jenis } \\
\text { Kelamin }\end{array}$ & $\begin{array}{c}\text { Umur } \\
\text { (th) }\end{array}$ \\
\hline P1 & Perempuan & 47 th \\
\hline P2 & Perempuan & 29 th \\
\hline P3 & Perempuan & 43 th \\
\hline P4 & Perempuan & 40 th \\
\hline P5 & Perempuan & 35 th \\
\hline
\end{tabular}

Dalam penelitian ini terdapat 10 butir pertanyaan yang diajukan saat melakukan kegiatan proses wawancara.

\begin{tabular}{|l|l|}
\hline No. & \multicolumn{2}{|c|}{ Pertanyaan } \\
\hline $\mathbf{1}$ & $\begin{array}{l}\text { Apa bahan dasar yang } \\
\text { dibuat untuk membuat kain }\end{array}$ \\
\hline
\end{tabular}

\begin{tabular}{|c|c|}
\hline & tenun? \\
\hline 2 & $\begin{array}{ll}\text { Mengapa } & \text { masih } \\
\text { mempertahankan } & \text { untuk } \\
\text { membuat kain tenun } & \\
\text { dengan alat tradisional? }\end{array}$ \\
\hline 3 & $\begin{array}{l}\text { Sejak kapan perempuan } \\
\text { Desa Sukarara belajar } \\
\text { membuat kain tenun? }\end{array}$ \\
\hline 4 & $\begin{array}{l}\text { Apakah menjadi suatu } \\
\text { kewajiban bagi perempuan } \\
\text { Desa Sukarara untuk mahir } \\
\text { membuat tenun? }\end{array}$ \\
\hline 5 & $\begin{array}{l}\text { Berasal dari mana } \\
\text { pembuatan benang tenun? }\end{array}$ \\
\hline 6 & $\begin{array}{l}\text { Berasal dari mana zat } \\
\text { warna yang dipakai untuk } \\
\text { membuat benang tenun? }\end{array}$ \\
\hline 7 & $\begin{array}{l}\text { Apakah pewarna yang } \\
\text { digunakan berbahaya bagi } \\
\text { lingkungan? }\end{array}$ \\
\hline 8 & $\begin{array}{l}\text { Kemanakah pembuangan } \\
\text { limbah dari hasil } \\
\text { pembuatan benang tenun? }\end{array}$ \\
\hline 9 & $\begin{array}{l}\text { Apakah ketika sebagian } \\
\text { alam dijadikan modal } \\
\text { untuk pembuatan tenun } \\
\text { tradisional, terdapat proses } \\
\text { pelestarian alam kembali? }\end{array}$ \\
\hline 10 & $\begin{array}{l}\text { Kontribusi apa yang } \\
\text { sedang atau akan dilakukan } \\
\text { agar kelestarian alam Desa }\end{array}$ \\
\hline
\end{tabular}




\section{Sukarara tetap terjaga?}

Respon Partisipan

Nilai ekofeminis dalam penelitian ini dapat dilihat dari keterkaitan antara perempuan desa dengan alam berdasarkan pengalaman hidup yang dilakukan dalam keseharian. Berdasarkan instrumen penelitian yang telah dibuat, berikut ini beberapa jawaban yang didapatkan peneliti dari kegiatan wawancara, diantaranya:

\section{Pertanyaan 1}

Apa bahan dasar yang dibuat untuk membuat kain tenun?

"ini dari benang tumbuhan di kebun" (P1)

"dari benang tradisional"

"dari benang yang sudah jadi di pasar” (P3)

“benang alam”(P4) (P5)

Berdasarkan jawaban dari partisipan telah menyebutkan bahwa benang yang dipakai untuk membuat kain tenun suku Sasak berasal dari benang tradisional yang terbuat dari bahanbahan alami, hal ini telah menunjukkan bahwa terdapat kaitan antara perempuan dan alam.

\section{Pertanyaan 2}

Mengapa masih mempertahankan untuk membuat kain tenun dengan alat tradisional?

"sudah dari sana nya”(P1)

(P3) (P4)

"dari Zaman dulu sudah

seperti ini” (P2)

"dari dulu seperti ini” (P5)

Berdasarkan jawaban dari partisipan telah menyebutkan bahwa mempertahankan pembuatan kain tenun dengan alat tradisional merupakan warisan nenek moyang dan mereka berusaha menjaganya. Hal ini menunjukkan bahwa perempuan suku sasak berusaha untuk melestarikan pembuatan secara tradisional dan terkait dengan alam.

\section{Pertanyaan 3}

Sejak kapan perempuan Desa Sukarara belajar membuat kain tenun?

"dari umur 10 tahun harus bisa" (P1) (P2) 
"dari kecil harus diajarkan, syarat nikah"(P3)

"tidak boleh menikah kalo gak bisa..jadi dari kecil diajarin" (P4)(P5)

Berdasarkan jawaban dari partisipan telah menyebutkan bahwa belajar membuat kain tenun sudah diajarkan dari kecil sebagai syarat untuk menikah, karena jika tidak bisa membuat kain tenun tidak boleh menikah terlebih dahulu. Hal ini menandakan bahwa mengajarkan untuk terkait dengan alam sudah dilakukan sejak dini.

\section{Pertanyaan 4}

Apakah menjadi suatu kewajiban bagi perempuan Desa Sukarara untuk mahir membuat tenun?

“iya..syarat nikah" $(P 1)(P 2$ (P5)

"anak perempuan saya seтиa harus bisaa..saya ajarin mereka.."(P3)

"harus bisa..syarat nikah ya harus bisa"(P4)

Berdasarkan jawaban dari partisipan telah menyebutkan bahwa belajar membuat kain tenun sudah diajarkan dari kecil sebagai syarat untuk menikah, sama halnya dengan jawaban parda pertanyaan nomer 3 . Hal ini menandakan bahwa mengajarkan untuk terkait dengan alam sudah dilakukan sejak dini.

\section{Pertanyaan 5}

Berasal dari mana pembuatan benang tenun?

"dari tumbuhan di

kebun...dari pasar

juga”(P2)(P3)(P4)

“dulu saya buat sendiri

benang dari kapas

sendiri..tapi kebun nya

terbakar..jadi sekarang beli

dari pasar"(P5)

"saya sudah gak sanggup

bikin sendiri,, beli dari pasar

aja" (Pl)

Berdasarkan jawaban dari partisipan telah menyebutkan bahwa pembuatan benang tenun dari tumbuhan kapas yang ditanam sendiri, seiring dengan tambahnya usia mereka mencari cara praktis untuk membeli benang yang sudah dipintal dari pasar. Hal ini 
menunjukkan perempuan sudah terlibat dengan alam.

\section{Pertanyaan 6}

Berasal dari mana zat warna yang dipakai untuk membuat benang tenun?

"banyak..dari kulit pohon juga bisa, tergantung warna apa” $(P 2)(P 4)(P 5)$

"biasanya bisa dari daun..diancurin, direndem kalo mau warna hitam benangnya" (P1)

“dari biji juga bisa”(P3)

Berdasarkan jawaban dari partisipan telah menyebutkan bahwa pembuatan benang tenun berasal dari bahan alam. Hal ini menunjukkan perempuan sudah terlibat dengan alam.

\section{Pertanyaan 7}

Apakah pewarna yang digunakan berbahaya bagi lingkungan?

"ya nggak, kan dari pohon.."

$(P 2)(P 4)(P 5)$

"nggak, dari daun yang dihancurin jadi gak bahaya"(P1)

“nggak bahaya”(P3)
Berdasarkan jawaban dari partisipan telah menyebutkan bahwa pemilihan pembuatan pewarna benang berasal dari alam sehingga tidak membahayakan lingkungan. Hal ini menunjukkan perempuan suku Sasak sudah mengerti untuk menjaga alam.

\section{Pertanyaan 8}

Kemanakah pembuangan limbah dari hasil pembuatan benang tenun?

"dibuang dibelakang aja pas bikin sendiri dulu” (P3)

"Sekarang gak tau, kan beli dari pasar " $(P 1)(P 2)$

"dulu dibuang aja di tanah, sekarang beli jadi"(P5)

Berdasarkan jawaban dari partisipan telah menyebutkan bahwapembuangan sisa pewarna benang tidak memerlukan tempat khusus, hanya dibuang di sekitar lingkungan tempat tinggal. Hal ini menunjukkan perempuan suku Sasak sudah mengerti bahwa jika membuang bahan yang berasal dari alam tidak berbahaya jadi tidak perlu tempat khusus.

\section{Pertanyaan 9}

Apakah ketika sebagian alam dijadikan modal untuk pembuatan 
tenun tradisional, terdapat proses pelestarian alam kembali?

“iya suka ada nanam lagi" $(P 2)(P 3)$

"biasanya yang laki-laki ada kerja menanam di kebun"(Pl)

“ditanam lagi dikebun kalo ada benihnya"(P5) (P4)

Berdasarkan jawaban dari partisipan telah menyebutkan bahwa setelah mereka menggunakan bahan-bahan alam untuk pembuatan benang, terdapat kegiatan menanam kembali. Hal ini menunjukkan perempuan suku Sasak sudah mengerti untuk menjaga alam dan dibantu oleh kaum laki-laki. Terdapat kerja sama yang baik dalam menjaga alam antara kaum laki-laki dan perempuan suku Sasak, perempuan tidak berada dalam posisi yang memiliki kontrol rendah terhadap alam tetapi saling bekerja sama dengan kaum laki-laki.

\section{Pertanyaan 10}

Kontribusi apa yang sedang atau akan dilakukan agar kelestarian alam Desa Sukarara tetap terjaga?
"Tetap pake tradisonal,,biar gak ngerusak"(P2)(P4) "pake bahan tradisional dipertahanin,warisan nenek moyang juga"(P1) "nanam pohon lagi kalo udah ditebang bikin warna benang"'(P3)(P5)

Berdasarkan jawaban dari partisipan telah menyebutkan bahwa terdapat kesadaran akan kelestarian alam daerah tinggal mereka selain untuk menjaga warisan ennek moyang. Hal ini menunjukkan kontribusi perempuan dengan alam sudah terbentuk sejak dulu di suku Sasak.

\section{Perempuan suku Sasak dan alam}

Sebagian besar perempuan yang ada di Desa Sukarara ini bekerja sebagai penenun. Untuk menjaga dan melestarikan budaya dan tenun tradisional yang diwarisi oleh nenek moyang mereka maka para perempuan di Desa Sukarara ini diwajibkan untuk belajar menenun, bahkan sejak masih usia anak-anak para orang tua mereka telah mewariskan keterampilannya dan 
mengajarkan kepada anak-anak perempuan mereka menenun dengan motif awal atau motif dasar yang sangat sederhana untuk lebih mudah dipahami dan dipelajari oleh anakanak mereka bagaimana cara menenun yang baik dan benar untuk mendapatkan kualitas hasil tenunan yang baik nantinya. Pekerjaan menenun ini biasanya mereka lakukan di teras depan, dan kebiasaan ini masih mereka lakukan sampai saat ini. Pemandangan ini akan anda jumpai hampir pada setiap rumah yang ada disepanjang jalan Desa Sukara yang anda lewati. Kain tenun atau songket dari DesaSukarara ini memiliki ciri khas tersendiri dengan desain atau motif yang berbeda dengan kain-kain tenun lainnya yang ada di Indonesia. Sebuah hasil karya kain tenun yang sangat indah dan artistik yang memiliki desain ekslusif yang dihasilkan oleh tangan-tangan terampil dari para perempuan Desa Sukarara. Dengan ciri khas khusus dan desain tradisional yang menggambarkan gaya hidup kuno pulau Lombok dengan motif rumah adat dan lumbung serta motif tokek, masih mereka pertahankan sampai saat ini. Walaupunhanya dengan menggunakan alat tenun tradisional yang sangat sederhana, namun hasil tenun dari Desa Sukarara ini memiliki kualitas yang sangat baik dan sangat mengagumkan. Desain kain tenun Desa Sukarara ini memang diakui sangat mengesakan jika dilihat dari aplikasi pasangan warna-warna tanah dengan pola tradisional timur yang asli Pulau Lombok. Bahan baku yang mereka gunakan adalah benang katun, sutera, sutera emas dan benang sutera perak.

Pewarna alami pembuatan benang tenun

Bahan pewarna yang mereka gunakan adalah dari bahan pewarna alami sepertiwarna coklat kemerahan dari pohon mahoni, warna coklat muda dari batang jati, warna coklat tanah dari biji asam, warna coklat tua dari batang pisang busuk, dan warna ungu dari kulit manggis dan anggur. Hal inilah yang membuat kain tenun atau songket dari Desa Sukarara ini terkenal dengan ciri khas kain songket yang berpola cerah. Dan juga hasil tenun Desa Sukarara ini 
sudah banyak dikenal dan sangat dusukai oleh wisatawan mancanegara. Seperti yang anda ketahui bahwa di dalam pengerjaan menenun yang dilakukan di Desa Sukarara ini hanya menggunakan alat tenun tradisional yang sangat sederhana, maka harga kain tenun atau songket ini tergantung pada faktor kesulitan penentuan motif dan lamanya waktu pengerjaan. Hal inilah yang membuat harga kain tenun tradisional Desa Sukarara sangat mahal.

\section{Teknik Pembuatan kain tenun}

Pembuatan kain tenun secara klasik atau tradisional ini diawali dengan mempersiapkan pembuatan benang, berikut pembuatan zat warnanya juga. Pembuatan benang secara tradisional menggunakan pemberat yang diputar-putar dengan jari-jari tangan. Sementara pemberatnya sendiri berbentuk seperti gasing yang terbuat dari kayu atau terakota. Untuk bahan membuat benang mengggunakan kapas, kulit kayu, serat pisang, serat nanas, daun palem dan lain sebagainya. Untuk pembuatan zat warnanya sendiri terdiri dari dua warna yaitu biru dan merah. Warna biru didapatkan dari indigo/Mirinda

citrifonela/mengkudu.

Selain menggunakan mengkudu sebagai bahan pewarna, mereka juga menggunakan pewarna dari bahan tumbuhan lain seperti kesumba (sono keling). Pembuangan limbah pembuatan benang langsung dilakukan ke lingkungan karena tidak membahayakan.

Kontribusi Perempuan suku Sasak terhadap alam

Kontribusi yang sedang dan akan dikukan oleh perempuan Desa Sukarara adalah tetap mempertahankan warisan nenek moyang dengan tetap membuat kerajinan tenun dari bahan alami agar tidak membahayakan lingkungan sekitar. Dengan penggunaan bahan tradisonal dalam pembuatan kerajinan tenun oleh masyarakat perempuan Desa Sukarara, maka kegiatan tenun secara tidak langsung dapat mengurangi dampak dari perubahan iklim yang dapat diakibatkan oleh adanya pencemaran bahan kimia 
yang tidak bisa terdegradasi oleh alam. Pelestarian kerajinan tenun dengan mempertahankan warisan nenek moyang dengan tetap menggunakan bahan alami sangat membantu dalam menjaga keseimbangan alam. Perubahan iklim lingkungan dunia yang semakin mengkhawatirkan perlu mendapatkan perhatian khusus dan serius. Kegiatan tenun tradisional telah membuat suatu pembiasaan yang dapat mengurangi dampak dari perubahan iklim global dengan mengurangi penggunaan bahan kimia yang membahayakan lingkungan. Oleh karena itu kegiatan tenun ini harus tetap dibina agar tidak terjadi perubahan dalam mekanisme pembuatan dengan mempertahankan bahan alami.

\section{KESIMPULAN}

Jiwa ekofeminisme di Desa Sukarara sudah terbentuk dari dahulu sejak nenek moyang mereka dimana mereka mencintai lingkungan dengan tetap mempertahankan pembuatan tenun tradisonal sampai sekarang. Perempuan yang bertindak sebagai pengelola alam untuk tujuan sosial ekonomi penunjang kehidupan mereka. Penggunaan bahan tradisonal dalam pembuatan kerajinan tenun oleh masyarakat perempuan Desa Sukarara dapat mengurangi dampak dari perubahan iklim global karena penggunaan bahan kimia yang merusak lingkungan. Maka kegiatan tenun secara tidak langsung dapat mengurangi dampak dari perubahan iklim yang dapat diakibatkan oleh adanya pencemaran bahan kimia yang tidak bisa terdegradasi oleh alam. Pelestarian kerajinan tenun dengan mempertahankan warisan nenek moyang dengan tetap menggunakan bahan alami sangat membantu dalam menjaga keseimbangan alam. Perubahan iklim lingkungan dunia yang semakin mengkhawatirkan perlu mendapatkan perhatian khusus dan serius. Kegiatan tenun tradisional telah membuat suatu pembiasaan yang dapat mengurangi dampak dari perubahan iklim global dengan mengurangi penggunaan bahan kimia yang membahayakan lingkungan. Oleh karena itu kegiatan tenun ini harus tetap dibina agar tidak terjadi 
perubahan dalam mekanisme pembuatan dengan mempertahankan bahan alami. Jika pembinaan terus dilakukan secara terus menerus pada keturunannya, maka dapat dipastikan peran perempuan desa Sukarara dalam menjaga alam dapat dilestarikan dan dipertahankan.

\section{DAFTAR PUSTAKA}

Aminah. 2017. Mengenal Keindahan Lombok Lewat Kain Tenunnya. aminahsurabaya.wordpress.co m (1 Mei 2017)

Anonim. 2015. Memlihat Pembuatan Tenun di Desa Sade. Tersedia di : (thelangkahtravel.com) (9 Mei 2017)

Anonim. Belajar Menenun di Lombok. http://id.lombokindonesia.org (1 Mei 2017)

Braimmer, Leila. Ecofeminism, The Environment, And Social MovementsPaper presented at the National Communication Association 1998 Convention, New York, NY.

Dana, Devina. 2013. Perempuan dan Lingkungan. Tersedia di : (http://perempuan.sabda.org) (9 Mei 2017)

Dian, Asti. 2016. Hebatnya Perempuan dalam Pengelolaan Lingkungan. Tersedia online di
: http://www.mongabay.co.id (1 Mei 2017)

Down to Earth. 2004. Perempuan, Tanah, dan Sumber Daya Alam. Tersedia di : downtoearth-indonesia.org (9 Mei 2017)

King, Y. (1990). Healing the wounds: Feminism, ecology, and the nature/culture dualism. In I. Diamond \& G. F. Orenstein (Eds.), Reweaving the world: The emergence of ecofeminism (pp. 106-121). San Francisco: Sierra Club Books

Morgan, J. (1992). Ecofeminism an emerging social movement. Unpublished Plan B paper, Anthropology Department, University of Minnesota, Minneapolis, $M N$.

Putu Darma, I Dewa. 2015. Keragaman Tumbuhan sebagai Pewarna pada Kerajina Tenun Suku Sasak : Studi Kasus di Desa Sukarara, Kecamatan Joggat, Kabupaten Lombok Tengah, Nusa Tenggara Barat. Volume 1 No.4, Juli 2015 Halaman 753-756.

Rinoza, Renal. 2016. Perempuan dan Lingkungan: Memahami Bumi sebagai Kerahiman; Suatu Upaya untuk Kembali Pulang ke Rahim Ibu Pertiwi. Tersedia online di : http://readersblog.mongabay.co .id (2 Mei 2017) 
Syaddad, Irza. 2014. Perempuan, Alam dan Kedaulatan.

Tersedia di zirniirza.wordpress.com (9 Mei 2017
Warren, J Karen. 1993. Introduction to Ecofeminist. Tersedia di :http://media.pfeiffer.edu (2 Juni 2017) 